\title{
Short communication: Effect of heat stress on nonreturn rate of Italian Holstein cows
}

\author{
S. Biffani, ${ }^{*}$ U. Bernabucci, $†$ A. Vitali, $\uparrow$ N. Lacetera, $\dagger$ and A. Nardone ${ }^{1}$ \\ *Istituto di Biologia e Biotecnologia Agraria (IBBA), Consiglio Nazionale delle Ricerche (CNR), Via Einstein - Località Cascina Codazza, \\ 26900 Lodi, Italy \\ †Dipartimento di Scienze Agrarie e Forestali (DAFNE), Università degli Studi della Tuscia-Viterbo, 01100, Viterbo, Italy
}

\section{ABSTRACT}

The data set consisted of $1,016,856$ inseminations of 191,012 first, second, and third parity Holstein cows from 484 farms. Data were collected from year 2001 through 2007 and included meteorological data from 35 weather stations. Nonreturn rate at $56 \mathrm{~d}$ after first insemination (NR56) was considered. A logit model was used to estimate the effect of temperature-humidity index (THI) on reproduction across parities. Then, least squares means were used to detect the THI breakpoints using a 2-phase linear regression procedure. Finally, a multiple-trait threshold model was used to estimate variance components for NR56 in first and second parity cows. A dummy regression variable $(t)$ was used to estimate NR56 decline due to heat stress. The NR56, both for first and second parity cows, was significantly (unfavorable) affected by THI from $4 \mathrm{~d}$ before $5 \mathrm{~d}$ after the insemination date. Additive genetic variances for NR56 increased from first to second parity both for general and heat stress effect. Genetic correlations between general and heat stress effects were -0.31 for first parity and -0.45 for second parity cows.

Key words: dairy cow, temperature-humidity index breaking point, heat stress, reproduction trait, heritability

\section{Short Communication}

Declining fertility of dairy cows represents a major concern among producers due to the effect on the profitability of the herd, leading to increased culling rates, larger veterinary expenses, and reduced genetic potential. Indeed, heat stress due to warm environment is one of the major factors that can negatively affect production, reproduction, and health of dairy cows (Bernabucci et al., 2010). The temperature-humidity

\footnotetext{
Received October 6, 2015

Accepted March 9, 2016.

${ }^{1}$ Corresponding author: nardone@unitus.it
}

index (THI), which represents the combined effects of air temperature and humidity (Armstrong, 1994), is generally used as a bioclimatic index (Hahn et al., 2003). In a comprehensive review by Hansen (2007), the deleterious effects of heat stress on oocyte development and maturation, on early embryonic death, and on fetal or placental development were elucidated. This author highlighted 2 specific aspects: the time at which the heat stress occurs (e.g., before or after the insemination event) and the role of genetics.

Jordan (2003) reported that negative effects of heat stress could be detected as early as $42 \mathrm{~d}$ before insemination until $40 \mathrm{~d}$ after. Ravagnolo and Misztal (2002) reported that THI on the day of insemination seems to be the most informative weather parameter to be used for reproduction studies. However, they stressed that geographical variations do exist and the right parameter should be estimated from actual data.

Apart from the onset of heat stress effect and its further implications on reproductive traits, some studies (Nardone and Valentini, 2000; Ravagnolo and Misztal, 2002a; Bernabucci et al., 2014) have demonstrated the existence of both a genetic component of heat tolerance and its negative genetic relationship with production and reproduction. Moreover, the onset of heat stress varies between and within animals (Aguilar et al., 2009), as well as between traits and parities, depending on their physiological status (Bernabucci et al., 2014).

Recently, Bernabucci et al. (2014) proposed a 2-phase linear regression procedure to detect THI thresholds in production traits to estimate variance components for heat tolerance and to infer its genetic relationship with milk production traits in Italian Holstein cows.

The objective of the present study was to investigate the effect of heat stress on a reproductive trait, namely, nonreturn rate at $56 \mathrm{~d}$ after first insemination (NR56), to detect the threshold point and time period when NR56 of primiparous and multiparous Italian Holstein cows are affected by heat stress and to estimate its genetic component. The most controversial issue regarding fertility is which is the best trait to be used. This is due to the fact that female fertility is quite a complex 
trait and several indicator traits have been proposed for its evaluation. Among them, nonreturn rate within $56 \mathrm{~d}$ after first insemination (NR56) has been internationally recommended and widely used to assess the ability of conception and maintaining pregnancy over the period of early gestation (Miglior, 1999; Jorjani, 2006; Biffani and Canavesi, 2007; Tiezzi et al., 2015). Moreover, as Andersen-Ranberg et al. (2005) pointed out, this NR56 data are less biased due to selection and have fewer missing records than other fertility traits. On the other side, the main disadvantage is that a cow that does not return within $56 \mathrm{~d}$ might not be pregnant or get a subsequent calving (Sun and Su, 2010). Currently, the NR56 is the trait officially used in the national genetic evaluation for fertility in the Italian Holstein breed, and in other 13 countries worldwide (Interbull, 2016).

Data were provided by the Italian Holstein Breeder Association and comprised 1,016,856 inseminations of 191,012 Holstein cows (first, second, and third parity) from 484 farms, collected from 2001 through 2007. Nonreturn rate at 56-d after first insemination was calculated for all cows. First, second, and third parity cows were retained for successive analysis. A value of 1 was assigned to cows that did not return to insemination (assumed pregnant) and 0 for cows that were inseminated a second time within $56 \mathrm{~d}$. A detailed description of the rules used to validate fertility traits that relied on insemination information is given in Biffani et al. (2003). The weather data were obtained from 35 meteorological stations located within a maximum of $5 \mathrm{~km}$ from each herd. Data consisted of daily weather information over a 7-yr period (2001-2007). Briefly, THI index was calculated using the following formula:

$$
\begin{aligned}
\mathrm{THI}= & (1.8 \times \mathrm{AT}+32)-(0.55-0.55 \times \mathrm{RH}) \\
& \times[(1.8 \times \mathrm{AT}+32)-58],
\end{aligned}
$$

where AT is the ambient temperature $\left({ }^{\circ} \mathrm{C}\right)$, and $\mathrm{RH}$ is the relative humidity as a fraction of the unit. With respect to the original equation, this formula includes terms $(1.8 \times \mathrm{AT}+32)$ that account for conversion of temperature data from degrees Celsius $\left({ }^{\circ} \mathrm{C}\right)$ to degrees Fahrenheit $\left({ }^{\circ} \mathrm{F}\right)$. Maximum AT and minimum $\mathrm{RH}$ were used for calculating THI index. More details can be found in Bernabucci et al. (2014).

Reproduction data were merged with weather information, assigning each insemination record to the daily weather records at the nearest weather station. Weather station data provide an accurate source of ambient air temperature and relative humidity outside of dairy barns; however, the values within a barn can often be different as reported by Schüller et al. (2013). In the same study, high positive relationships were
Table 1. Descriptive statistics for temperature-humidity index by month of calving

\begin{tabular}{lcc}
\hline $\begin{array}{l}\text { Month } \\
\text { of calving }\end{array}$ & $\begin{array}{c}\text { Number } \\
\text { of animals }\end{array}$ & $\begin{array}{c}\text { Number } \\
\text { of records }\end{array}$ \\
\hline January & 3,015 & 5,056 \\
February & 4,784 & 7,547 \\
March & 6,867 & 9,924 \\
April & 8,809 & 13,077 \\
May & 7,946 & 11,460 \\
June & 6,111 & 8,742 \\
July & 5,931 & 8,426 \\
August & 7,278 & 11,003 \\
September & 8,328 & 13,523 \\
October & 7,641 & 13,081 \\
November & 6,676 & 11,071 \\
December & 3,557 & 6,285 \\
\hline
\end{tabular}

found between meteorological data and on-farm measurements confirming the validity of using data from meteorological stations in studies in which the sample is very large as in the present study. Age intervals were established for each parity according to the following thresholds: 20 to 36,31 to 50 , and 42 to 65 mo of age for first, second, and third parity cows, respectively. Additionally, cows were required to have no insemination before 14 or beyond $150 \mathrm{~d}$ from calving. Days in milk classes were defined as one class for every $30 \mathrm{~d}$, resulting in 11 classes. The weather data set was divided into 36 THI classes, with the first class beginning at $\mathrm{THI}=50$, and the subsequent classes were set at each 1 point THI thereafter until the last class, which was $\mathrm{THI}=85$. After editing, the final data set consisted of 119,195 NR56 records for 76,943 cows. Distribution of data across parities was $57.5,30.1$, and $12.4 \%$ for first, second, and third parity cows, respectively. Descriptive statistics of THI per month of calving are in Table 1 and Figure 1.

The effect of THI (heat stress) was analyzed by fitting the following logit model (model 1) using the GLIMMIX procedure in SAS version 9.2 (SAS, 2008):

$$
\begin{aligned}
& \operatorname{logit}\left(p_{i j k l m n o}\right)=\eta+e=\mu+\operatorname{herd}(y i)_{i}+\operatorname{mc}(y i)_{j} \\
& +\operatorname{cdim}_{k}+\operatorname{thir}_{l}+\operatorname{age}_{m}+\operatorname{ord}_{n}+\operatorname{thir}_{l} \times \operatorname{ord}_{n} \\
& +\operatorname{cdim}_{k} \times \operatorname{ord}_{n}+b \times \operatorname{ecm}+e_{i j k l m n o},
\end{aligned}
$$

where $\operatorname{logit}()$ is the link function, $\log$ (odds), between the probability of either returning to insemination or not for cow $o$ in herd $i$, month of calving, and year of insemination $j$, days in milk $k$, THI $l$, age $m$, parity $n$, and the linear predictor $\eta$, where $\mu$ is the overall mean; $\operatorname{herd}(y i)_{i}$ is the random effect of herd nested within year of insemination $i$; $\operatorname{mc}(y i)_{j}$ is the fixed effect of month of calving nested within year of insemination $j$; $\operatorname{cdim}_{k}$ is the fixed effect of DIM class $k$; $\operatorname{thir}_{l}$ is the fixed effect of 
$\rightarrow$ North $\rightarrow$ Center $\rightarrow$-South

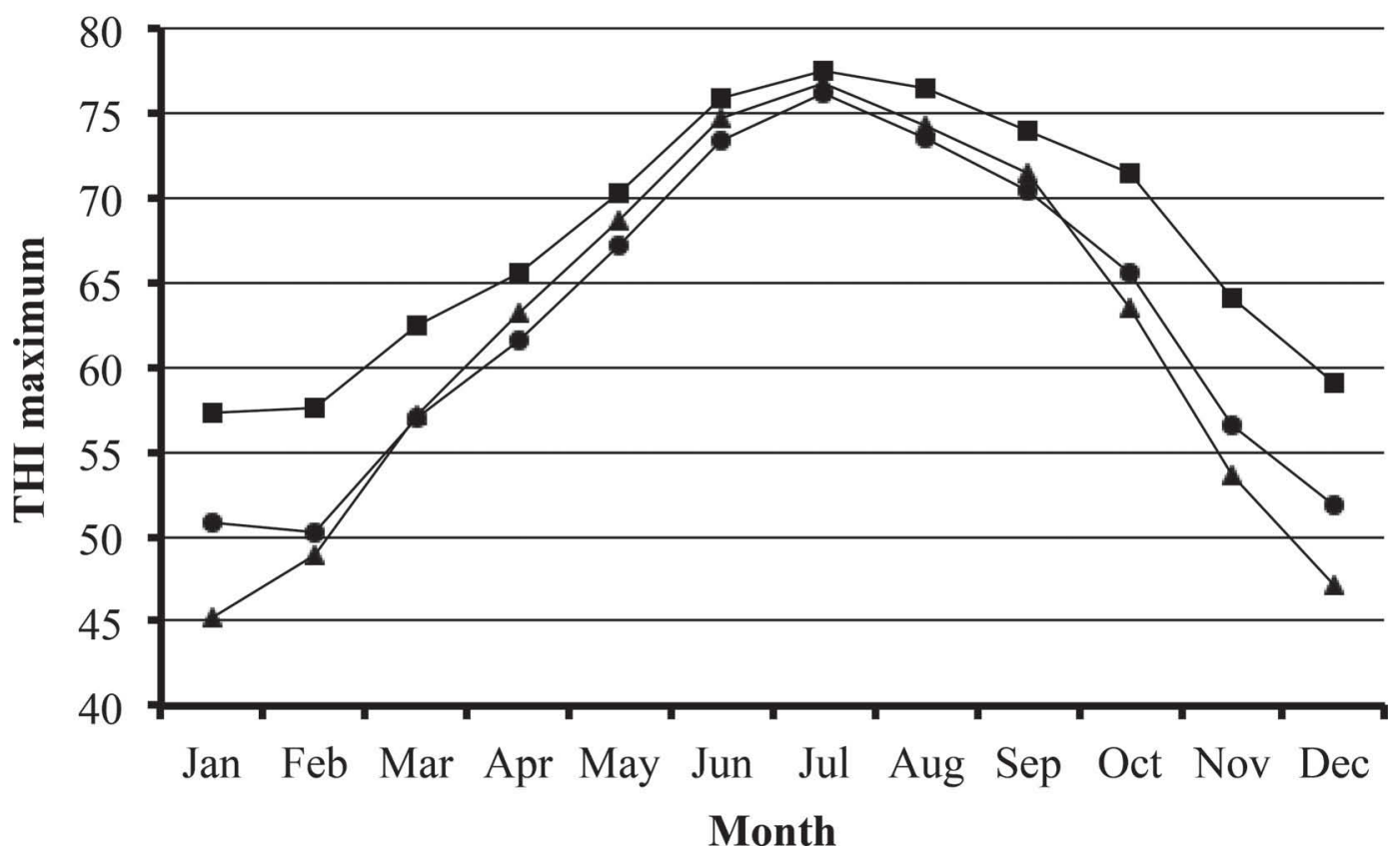

Figure 1. Changes of monthly average values of maximum temperature-humidity index (THI) in north, central, and south Italy.

THI class $l$; age $_{m}$ is the fixed effect age class $m$; $\operatorname{ord}_{n}$ is the fixed effect of parity $n$; $\operatorname{thir}_{l} \times \operatorname{ord}_{n}$ is the fixed effect of the THI class $l$ by parity class $n$; $\operatorname{cdim}_{k} \times \operatorname{ord}_{n}$ is the fixed effect of the DIM class $k$ by parity class $n$ class; $b$ is a fixed regression on daily energy-corrected milk (ecm), computed as suggested by Clay and McDaniel (2001); and $e_{i j k l m n o}$ is the random residual effect. A minimum of 24 records per herd-year of insemination was required. Least squares means of the fixed effect of the THI class $l$ by parity class $n$ were computed from model 1. The ILINK option from LSMEANS statement of PROC GLIMMIX was used to get estimates and their standard errors to be reported on the scale of the mean (the inverse linked scale). This option is very useful because it allows obtaining estimates of predicted probabilities and their standard errors in logistic models. A 2-phase linear regression procedure was then applied to least squares means from model 1 to detect the exact THI at which NR56 was affected. Package "strucchange" (Zeileis et al., 2002), implemented in R software (http://CRAN.R-project.org), was used for data analysis. The effect of THI on NR56 in first, second, and third parity cows was also investigated $16 \mathrm{~d}$ before and $16 \mathrm{~d}$ after the insemination date, respectively. The idea of using a 2-phase linear regression, as proposed by Bernabucci et al. (2014), is based on the observation that the relationship between an environmental parameter (e.g., THI) and the response to that parameter (e.g., nonreturn rate) might not be correctly detected by a simple graphical inspection or by a standard linear regression. If, for example, THI and nonreturn rate are linearly related, a simple linear regression can be used to model their relationship. However, if we observe that above a particular THI value, the nonreturn rate increases faster than before (i.e., the slope before and after the THI value is not the same), a simple linear regression may not provide an adequate and accurate pattern description. Moreover, it will not be able to identify the THI value at which the slope of the linear function changes (i.e., the break point). In this kind of situation, the following model can be used: $y_{i}=x_{i}^{T} \beta+u_{i}(i=1, \ldots, n)$, where $x_{i}^{T}$ is a $k \times 1$ vector of regressors, with the first component usually equal to unity; $\beta$ is the $k \times 1$ vector of regression coefficients (THI values); at time $i, y_{i}$ is the observation of the dependent variable (NR56), $x_{i}$ is a $k \times 1$ vector of $n$ regressors (THI values), and $\beta_{i}$ is the $k \times 1$ vector of regression coefficients, which may vary over time, and $u_{i}$ are $\operatorname{iid}\left(0, \sigma^{2}\right)$. The hypothesis being tested is that the regression coefficients remain constant (reduced model): $H_{0}: \beta_{i}=\beta_{0}(i=1, \ldots, n)$, compared with the alternative hypothesis that at least one coefficient varies over time (complete model). If the increase in sum of square errors, going from the complete to the reduced model, is significantly large, then the null hypothesis can be rejected, concluding that the complete model works well 
and a significant break point does exist (i.e., a significant change in NR56 due to THI has been detected).

Nonreturn rate at $56 \mathrm{~d}$ after first insemination of first and second parity cows was significantly affected by THI, by $4 \mathrm{~d}$ before and $5 \mathrm{~d}$ after the insemination (Table 2). No significant breakpoint was detected for third parity cows. Several authors have reported a general decrease in fertility performance with increase of parity number, hence suggesting that third parity cows have a lower nonreturn rate than first or second parity cows (Ravagnolo and Misztal, 2002b). The absence of THI break point in third parity cows is not easy to explain. Possible hypotheses are that the sensitivity to heat stress across parities is not the same and that THI thresholds may also be affected by several environmental factors (Bernabucci et al., 2014).

The THI breaking points ranged from 64 to 78, and 72 to 78 for first and second parity cows, respectively. On average, THI breaking point was smaller in first than second parity cows (73 vs. 75). Both first and second parity cows showed a drop in NR56 [Figure 2; i.e., a large proportion of cows returned to heat, namely the slope ( $b$ value in Table 2$)$ of the 2-phase linear regression related above]. The most critical period seems unfavorable THI effect is still detected after the day of insemination. Even if first parity cows are affected at a lower THI than second parity cows, the latter suffer from a greater NR56 drop, especially during the $3 \mathrm{~d}$ before insemination $(-0.087,-0.080,-0.081$ vs. -0.047 , $-0.051,-0.042$ for second and first parity cows, respectively). The observed and unfavorable effect of THI on reproduction confirms previous findings (al-Katanani et al., 1999; Ravagnolo and Misztal, 2002; Chebel et al., 2004). Those authors related that from 20 to $27 \%$ drop in conception rates or a decrease in 90-d nonreturn rate to the first service in lactating dairy cows occur during summer season, (i.e., when THI reaches its maximum value). Moreover, heat stress has also been associated with altered hormone secretion during the estrus cycle (Ronchi et al., 2001), impaired embryo development, and increased embryo mortality (Wolfenson et al., 2000; Hansen, 2007) in cattle. More recently, Schüller et al. (2014) showed how the conception rate of lactating dairy cows was negatively affected by heat stress both before and after the day of breeding. The THI thresholds of the present study were slightly different (higher) than those reported by Ravagnolo and Misztal (2002a,b) for nonreturn rate trait. This discrepancy might be due to several reasons. These include different experimental conditions, different methodological approach to detect the actual THI breaking point, and different number of days (56 vs. 90) to declare the successful insemination. to be within $4 \mathrm{~d}$ before the insemination. However, the

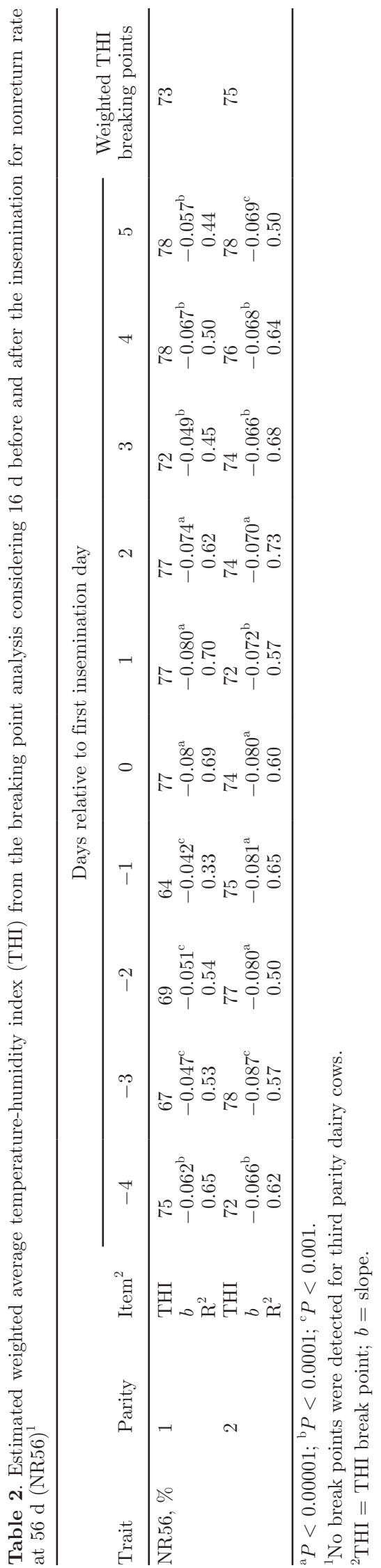




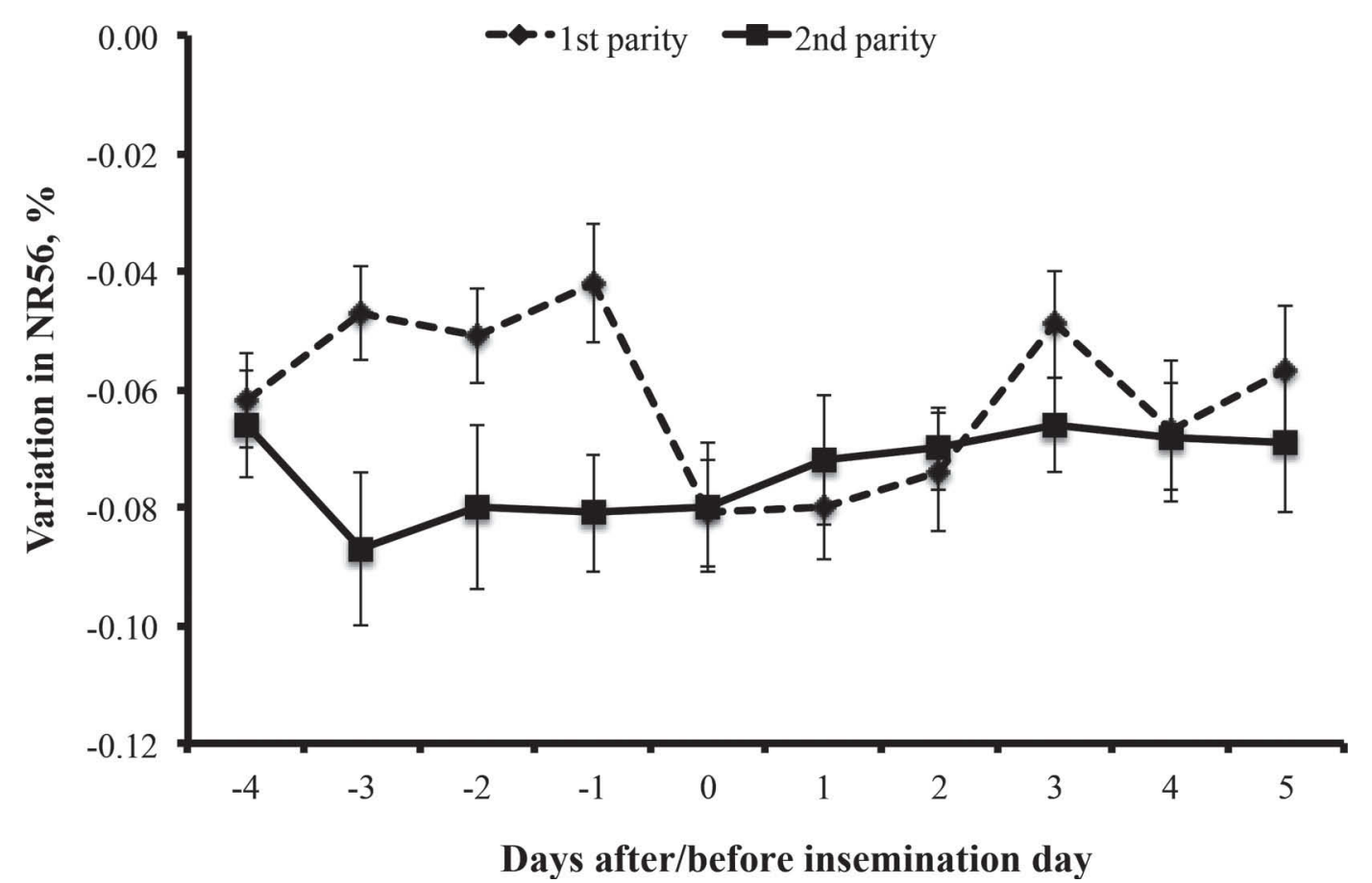

Figure 2. Variation of 56-d nonreturn rate (NR56) estimated by using the weighted temperature-humidity index breaking point for first and second parity cows, considering $4 \mathrm{~d}$ before and $5 \mathrm{~d}$ after the insemination day. Error bars indicate \pm SD.

With regard to this last point, using 56 d may lead to relying on some false positive records.

After the detection of the THI breaking points, a multiple trait threshold model was fitted to estimate and quantify the genetic relationship between heat stress and NR56 (model 2). A dummy regression variable $(t)$ was defined and included in the model to estimate the variation of NR56 due to heat stress. If the observed THI was below a particular THI threshold, a value of 0 was assigned to the variable $t$ (i.e., no heat stress), whereas if the observed THI was above such threshold, variable $t$ was the difference between the observed THI and that particular threshold. No THI breakpoint was observed in third parity cows, hence only first and second parities were included in the analyses using as THI breaking point 73 and 75 , respectively. Those thresholds were obtained by averaging the THI values within $4 \mathrm{~d}$ before and $5 \mathrm{~d}$ after the day of insemination (Bernabucci et al., 2014). Model 2 was as follows:

$$
\begin{aligned}
& y_{i j k l m n o}=\operatorname{htd}_{i j}+\operatorname{dim}_{k}+\operatorname{age}_{j m}+\operatorname{mi}_{l}(y i)_{n m} \\
& +\mathrm{f}(\mathrm{ecm}) b_{j o}+\mathrm{a}_{j p}+\mathrm{v}_{j p}\left[\mathrm{f}(\mathrm{THI})_{i}\right]+e_{i j k l m n o p},
\end{aligned}
$$

where $\mathrm{y}_{\mathrm{ijk} \text { lmno }}$ is NR56 after first insemination for cow $p$ in age class $\mathrm{m}$ within parity $j(1$ or 2$)$ and dim class $k$ for herd test-day $i$ within parity $j$ and month of insemination $l$ nested within year of insemination $m$ within parity $j$; htd is the fixed effect of herd test-day within parity; mi $(y i)$ is the fixed effect of month of insemination nested within year of insemination; dim is the fixed effect of DIM class; age is the fixed effect of age class; $\mathrm{f}(\mathrm{ecm})$ is the function for the linear effect of energy-corrected milk within parity; a is the effect of the additive genetic merit of cow within parity; $v$ is additive effect of heat tolerance of cow within parity; $\mathrm{f}(\mathrm{THI})_{i}$ is the heat stress function at THI of test-day $i$; and $e_{i j k l m n o p}$ is the residual. Let $\mathbf{a}^{\prime}=\left[\begin{array}{ll}a^{\prime}{ }_{j o} & \nu_{j o}\end{array}\right]$ be the vector of random additive genetic effects for parities $j$ $=1$ to 2 . The (co)variance structure was

$$
\operatorname{Var}\left|\begin{array}{l}
a \\
e
\end{array}\right|=\left[\begin{array}{cc}
\mathbf{A} \otimes \mathbf{G}_{\mathbf{0}} & 0 \\
0 & \mathbf{I} \otimes \mathbf{R}_{\mathbf{0}}
\end{array}\right]
$$

where $\mathbf{A}$ is the numerator relationship matrix; $\mathbf{G}_{\mathbf{0}}$ is 4 $\times 4$ matrices of (co)variances for additive effects; $\mathbf{I}$ is the identity matrix; and $\mathbf{R}_{\mathbf{0}}$ is a $\mathbf{a}^{\prime}=\left[\begin{array}{ll}\mathbf{a}^{\prime}{ }_{j o} & \nu_{j o}\end{array}\right]$ diagonal matrix of residual variances corresponding to each trait. Residual variances equal to 1 (Gianola and Foulley, 1983) were assumed. A minimum of 10 records per herd-year of insemination and 20 daughters per sire were required to estimate variance components. Variance component estimation was performed using the THRGIBBS1F90 software of Tsuruta and Misztal (2006) that implements a Gibbs sampling algorithm 
and allows for different combinations of continuous and threshold traits.

Parameter values for NR56 are given in Table 3. Additive genetic variances for NR56 increased from first to second parity both for general and heat stress effect. Heritability estimates for NR56 trait were 0.024 and 0.095 for first and second parity, respectively. Those values agree with previous findings (Jamrozik et al., 2005). Heritability for second parity cows seems to be a little bit overestimated. Even if Jamrozik et al. (2005) stressed the fact that heritability obtained using threshold models is usually higher than those obtained with linear models, additional reasons are possible. Nonreturn rate at $56 \mathrm{~d}$ considers as successful those inseminations that are not followed by a subsequent breeding within $56 \mathrm{~d}$, without validation through subsequent calving. In case of a second parity cows, this value might be favorably overestimated because it does not take into account the possible successive culling. Indeed, this hypothesis is supported by the average NR56 value for second parity cows, which was lower than first parity cows (Table 3).

Genetic correlation between NR56 after first insemination for first and second parity cows, as expected, was very strong $\left(r_{g}=0.90\right)$. Moreover, genetic correlations $\left(\mathrm{r}_{\mathrm{o} \text {-THI }}\right)$ between general and heat stress effects with NR56 were -0.31 and -0.45 for first and second parity cows, respectively. These results confirm the negative (genetic) effect of heat stress on reproductive efficiency.

Ravagnolo and Misztal (2002b) used data from multiparous cows, but they fitted a repeatability model. Indeed, they analyzed jointly the nonreturn rate of primiparous and multiparous cows, including in the model the parity fixed effect. Their results showed that primiparous cows were more sensitive to THI increase. In the present study, the reverse was true. The effect of heat stress was stronger on multiparous than primiparous (higher negative genetic correlation). Those results are quite interesting and support the hypothesis by Aguilar et al. (2010) that if records of later parities are going to be used they should be treated as a separate trait. This will model the different behavior observed across parities, leading to more reliable results.

Recently, in 2 different and independent studies, Biffani et al. (2015) and Dikmen et al. (2015) identified several specific genetic markers responsible for genetic variations in thermoregulation during heat stress. Those findings, obtained using DNA data (i.e., SNP), confirm results of the present study coming from a quantitative genetics approach (field data and classical pedigree data), suggesting a genetic component of heat stress.

In conclusion, heat stress represents a significant component of low fertility in dairy cattle. Indeed, both
Table 3. Estimates of variance components for 56-d nonreturn rate (NR56)

\begin{tabular}{|c|c|c|}
\hline \multirow[b]{2}{*}{ Parameter $^{1}$} & \multicolumn{2}{|c|}{ NR $56, \% \times 100$} \\
\hline & 1st parity & 2nd parity \\
\hline$\overline{\sigma_{\mathrm{a}}^{2}}$ & 0.024 & 0.095 \\
\hline$\sigma_{\text {thia }}^{2}$ & 0.015 & 0.013 \\
\hline$\sigma_{\text {a-thia }}^{2}$ & -0.006 & -0.026 \\
\hline$\sigma_{e}^{2}$ & 1 & 1 \\
\hline $\mathrm{r}_{\mathrm{g}-\text {-thi }}$ & -0.35 & -0.45 \\
\hline $\mathrm{h}_{\mathrm{a}}^{2}$ & 0.024 & 0.095 \\
\hline $\mathrm{h}^{2}{ }_{\text {thi }}$ & 0.0251 & 0.076 \\
\hline$r_{g}$ & \multicolumn{2}{|c|}{$\begin{array}{r}0.90 \\
\end{array}$} \\
\hline No. of cows & \multirow{2}{*}{\multicolumn{2}{|c|}{$\begin{array}{l}19,153 \\
56,271\end{array}$}} \\
\hline Animals in the pedigree & & \\
\hline Mean, \% & 54 & 48 \\
\hline $\mathrm{SD}$ & 49 & 49 \\
\hline
\end{tabular}

$\overline{\sigma^{1}{ }_{\mathrm{a}}}=$ additive genetic variance; $\sigma^{2}{ }_{\text {thia }}=$ additive genetic variance for temperature-humidity index (THI); $\sigma_{\text {a-thia }}^{2}=$ additive genetic covariance between the general effect and the effect of THI; $\sigma^{2}=$ residual variance; $r_{\alpha-t h i}=$ genetic correlation between the general effect and the effect of THI; $h^{2}{ }_{a}=$ general effect heritability; $h^{2}{ }_{\text {thi }}=$ heat stress heritability; $\mathrm{r}_{\mathrm{g}}=$ genetic correlation between NR56 in first and second parity cows.

first and second parity cows are unfavorably affected by hot environment before and after insemination day even if their sensitivity is not the same. Second parity cows start to be affected by heat stress at a threshold higher than first parity cows, but the effect on their NR56 is greater (i.e., the proportion of second parity cows who return to heat is larger). From a practical point of view, it is important for the farmer to know that a heat wave occurring after insemination can be as dangerous as a very hot period before insemination. Farmers usually try to avoid inseminating their cows during very hot periods, but knowing for how long a hot period might jeopardize the success of an insemination could help them in setting up the right management. So far, no genetic evaluation for heat stress resistance in dairy cattle is available worldwide; however, due to the increasing importance of animal welfare, a heat-tolerance trait should be included in the selection objective of dairy cattle populations.

\section{ACKNOWLEDGMENTS}

This study was supported by grants from Ministero delle Politiche Agricole, Alimentari e Forestali (MiPAAF, Rome, Italy: CLIMANIMAL and FACCE JPI-MACSUR2 projects).

\section{REFERENCES}

Aguilar, I., I. Misztal, and S. Tsuruta. 2009. Genetic components of heat stress for dairy cattle with multiple lactation. J. Dairy Sci. 92:5702-5711. 
Aguilar, I., I. Misztal, and S. Tsuruta. 2010. Genetic trends of milk yield under heat stress for US Holsteins. J. Dairy Sci. 93:17541758.

al-Katanani, Y. M., D. W. Webb, and P. J. Hansen. 1999. Factors affecting seasonal variation in 90-day nonreturn rate to first service in lactating Holstein cows in a hot climate. J. Dairy Sci. $82: 2611-2616$.

Andersen-Ranberg, I. M., G. Klemetsdal, B. Heringstad, and T. Steine. 2005. Heritabilities, genetic correlations, and genetic change for female fertility and protein yield in Norwegian dairy cattle. J. Dairy Sci. 88:348-355.

Armstrong, D. V. 1994. Heat stress interaction with shade and cooling. J. Dairy Sci. 77:2044-2050.

Bernabucci, U., S. Biffani, L. Buggiotti, A. Vitali, N. Lacetera, and A. Nardone. 2014. The effects of heat stress on Italian Holstein dairy cattle. J. Dairy Sci. 97:471-486.

Bernabucci, U., N. Lacetera, L. H. Baumgard, R. P. Rhoads, B. Ronchi, and A. Nardone. 2010. Metabolic and hormonal acclimation to heat stress in domesticated ruminants. Animal 4:1167-1183.

Biffani, S., U. Bernabucci, N. Lacetera, A. Vitali, P. Ajmone Marsan, N. P. P. Macciotta, and A. Nardone. 2015. A GWAS on heat tolerance phenotypes for Italian Holstein bulls. J. Anim. Sci. 93(Suppl. s3)/J. Dairy Sci. 98(Suppl. 2):649.

Biffani, S., and F. Canavesi. 2007. International genetic evaluation for fertility traits in dairy cattle. Ital. J. Anim. Sci. 6:47-49.

Biffani, S., A. B. Samore, F. Canavesi, and M. Marusi. 2003. Data quality assessment and preliminary investigations on fertility in the Italian Holstein Friesian. Pages 89-95 in Proc. Interbull Technical Workshop. Beltsville, MD. Interbull Bulletin No. 30.

Chebel, R. C., J. E. P. Santos, J. P. Reynolds, R. L. A. Cerri, S. O. Juchem, and M. Overton. 2004. Factors affecting conception rate after artificial insemination and pregnancy loss in lactating dairy cows. Anim. Reprod. Sci. 84:239-255.

Clay, J. S., and B. T. McDaniel. 2001. Computing mating bull fertility from DHI nonreturn data. J. Dairy Sci. 84:1238-1245.

Dikmen, S., X. Wang, M. S. Ortega, J. B. Cole, D. J. Null, and P. J. Hansen. 2015. Single nucleotide polymorphisms associated with thermoregulation in lactating dairy cows exposed to heat stress. J. Anim. Breed. Genet. 132:409-419.

Gianola, D., and J. L. Foulley. 1983. Sire evaluation for ordered categorical data with a threshold model. Genet. Sel. Evol. 15:201-224.

Hahn, G. L., T. L. Mader, and R. A. Eigenberg. 2003. Perspective on development of thermal indices for animal studies and management. EAAP Technical Series 7:31-44.

Hansen, P. J. 2007. Exploitation of genetic and physiological determinants of embryonic resistance to elevated temperature to improve embryonic survival in dairy cattle during heat stress. Theriogenology 68:S242-S249.

Interbull. 2016. Genetic evaluation. Female Fertility. Accessed Mar. 7, 2016. http://interbull.org/static/web/fertdoc1512r.pdf.

Jamrozik, J., J. Fatehi, G. J. Kistemaker, and L. R. Schaeffer. 2005. Estimates of genetic parameters for Canadian Holstein female reproduction traits. J. Dairy Sci. 88:2199-2208.

Jordan, E. R. 2003. Effects of heat stress on reproduction. J. Dairy Sci. 86:E104-E114.
Jorjani, H. 2006. International genetic evaluation for female fertility traits. Pages 57-34 in Proc. Interbull Technical Workshop, Wageningen, the Netherlands. Interbull Bulletin No. 34.

Miglior, F. 1999. Selection for fertility traits. Pages 110-114 in Proc. 24th Environmental Health Foundation of Canada (EHFC) Meeting, Auburn, Ontario.

Nardone, A., and A. Valentini. 2000. The genetic improvement of dairy cows in warm climates. Pages 185-191 in Proc. Joint ANPAEAAP-CHIEAM-FAO symposium. F. Guessous, N. Rihani, and A. Ilham, ed. EAAP publication no. 94, Wageningen Press, Wageningen, the Netherlands.

Ravagnolo, O., and I. Misztal. 2002. Studies on genetics of heat tolerance in dairy cattle with reduced weather information via cluster analysis. J. Dairy Sci. 85:1586-1589.

Ravagnolo, O., and I. Misztal. 2002a. Effect of heat stress on nonreturn rate in Holstein cows: Genetic analysis. J. Dairy Sci. 85:3092-3100.

Ravagnolo, O., and I. Misztal. 2002b. Effect of heat stress on nonreturn rate in Holsteins: Fixed-model analysis. J. Dairy Sci. 85:31013106 .

Ronchi, B., G. Stradaioli, A. Verini Supplizi, U. Bernabucci, N. Lacetera, P. A. Accorsi, A. Nardone, and E. Seren. 2001. Influence of heat stress or feed restriction on plasma progesterone, oestradiol-17 $\beta$, LH, FSH, prolactin and cortisol in Holstein heifers. Livest. Prod. Sci. 68:231-241.

SAS. 2008. SAS/STAT ${ }^{\circledR} 9.2$ User's Guide The GLIMMIX Procedure (Book Excerpt) Version 9.2. Edition 2008. SAS Inst. Inc., Cary $\mathrm{NC}$

Schüller, L. K., O. Burfeind, and W. Heuwieser. 2013. Short communication: Comparison of ambient temperature, relative humidity, and temperature-humidity index between on-farm measurements and official meteorological data. J. Dairy Sci. 96:7731-7738.

Schüller, L. K., O. Burfeind, and W. Heuwieser. 2014. Impact of heat stress on conception rate of dairy cows in the moderate climate considering different temperature-humidity index thresholds, periods relative to breeding, and heat load indices. Theriogenology 81:1050-1057.

Sun, C., and G. Su. 2010. Comparison on models for genetic evaluation of non-return rate and success in first insemination of the Danish Holstein cows. Livest. Sci. 127:205-210.

Tiezzi, F., C. Maltecca, A. Cecchinato, and G. Bittante. 2015. Comparison between different statistical models for the prediction of direct genetic component on embryo establishment and survival in Italian Brown Swiss dairy cattle. Livest. Sci. 189:6-13.

Tsuruta, S., and I. Misztal. 2006. THRGIBBS1F90 for estimation of variance components with threshold and linear models. J. Dairy Sci. 89(Suppl. 1):15.

Wolfenson, D., Z. Roth, and R. Meidan. 2000. Impaired reproduction in heat-stressed cattle: Basic and applied aspects. Anim. Reprod. Sci. 60-61:535-547.

Zeileis, A., F. Leisch, K. Hornik, and C. Kleiber. 2002. Strucchange: An $\mathrm{R}$ package for testing for structural change in linear regression models. J. Stat. Softw. 7:1-38. 